\title{
Shone's syndrome in an adult woman
}

\section{Síndrome de Shone en una mujer adulta}

\section{Pierina Quiroz-Zegarra ${ }^{1 *}$ y Violeta Illatopa-Cerna ${ }^{2}$}

${ }^{1}$ Cardiología; ${ }^{2}$ Servicio de Cardiología No Invasiva, Instituto Nacional Cardiovascular, Universidad Nacional Mayor de San Marcos. Lima, Perú

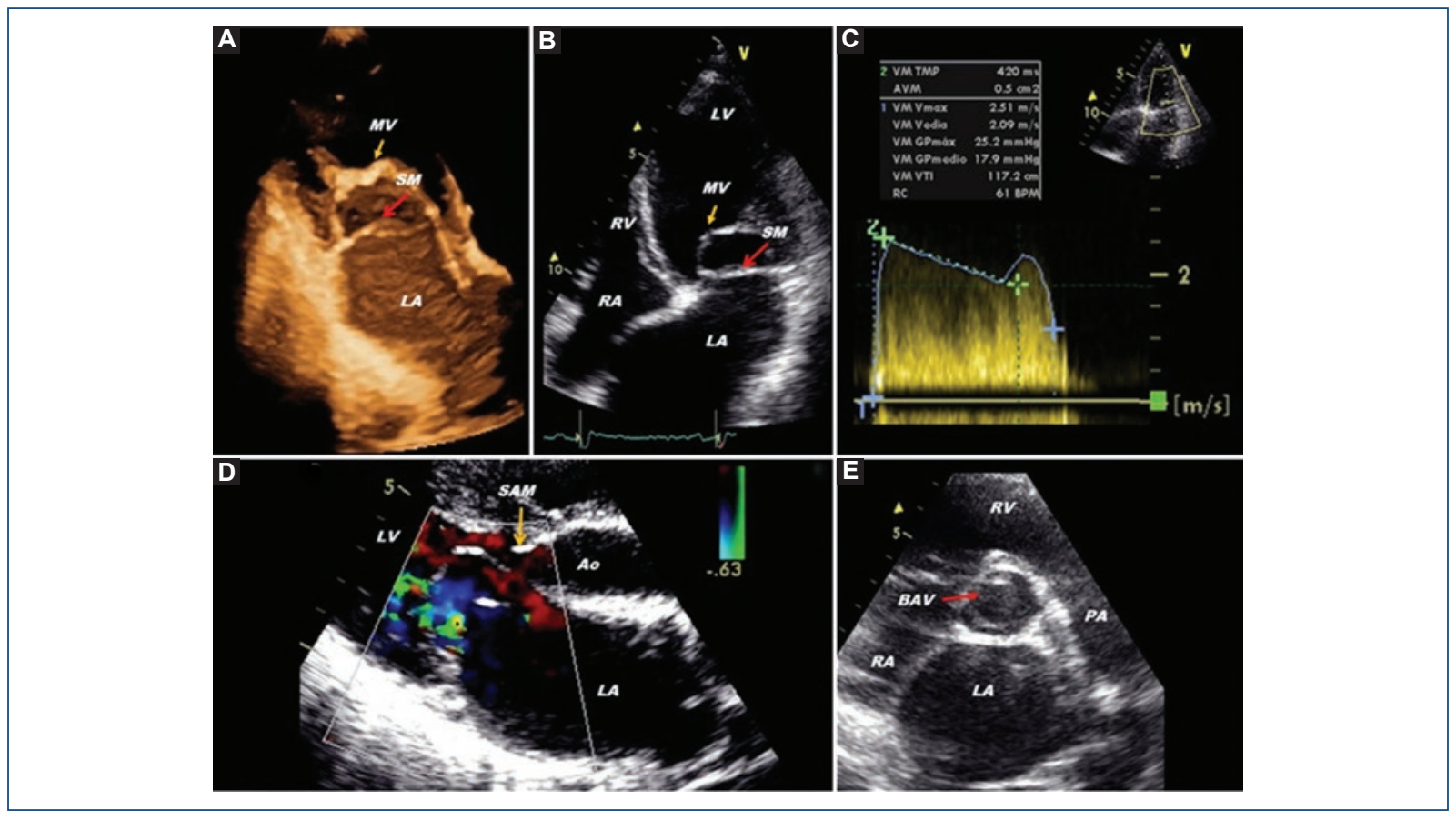

Figure 1. Transthoracic echocardiography. A: apical three-chamber view; B: apical four-chamber view; C: continuous Doppler, mitral valve gradient; D: parasternal long-axis color Doppler; E: parasternal short-axis view of aortic valve. BAV: bicuspid aortic valve; SM: supramitral membrane; MV: mitral valve; SAM: subaortic membrane; Ao: aorta; RA: right atrium; LA: left atrium; RV: right ventricle; LV: left ventricle; PA: pulmonary artery.

A 22-year-old woman with history of heart murmur diagnosed in childhood was referred from a general hospital with dizziness, palpitation, and worsening of dyspnea (NYHA III).

Transthoracic echocardiography (TTE) revealed large atria with supramitral, non-restrictive membrane that extends from the mitral annulus to the lower portion of the left atrial appendage (Fig.1 A-B, red.arrow. Video S1). Mitral valve showed thickened leaflets, both leaflets inserted into anterolateral papillary muscle, and hypoplastic posteromedial papillary muscle was present, so a parachute mitral valve was described. The Doppler

\section{Correspondencia:}

*Pierina Quiroz Zegarra

E-mail: pierinaqz@ hotmail.com
Fecha de recepción: 28-05-2019

Fecha de aceptación: 02-09-2019 DOI: 10.24875/ACM.19000235
Disponible en internet: 30-01-2020 Arch Cardiol Mex. 2020;90(1):86-87

www.archivoscardiologia.com

2604-7063/@ 2019 Instituto Nacional de Cardiología Ignacio Chávez. Publicado por Permanyer. Este es un artículo open access bajo la licencia CC BY-NC-ND (http://creativecommons.org/licenses/by-nc-nd/4.0/). 
demonstrated significant mitral stenosis (mean gradient $17 \mathrm{mmHg}$, and valve area $\left.0.5 \mathrm{~cm}^{2}\right)$ (Fig.1 C). Type I bicuspid aortic valve without raphe (Fig.1 E), non-restricted subaortic membrane (Fig.1 D, yellow. arrow. Video S2), aortic coarctation with gradient $28 \mathrm{mmHg}$ and non-diastolic prolongation, preserved left ventricular systolic function, and tricuspid regurgitation gradient $52 \mathrm{mmHg}$ were additional findings. Transesophageal echocardiography confirmed TTE diagnosis.

Cardiac catheterization showed pulmonary capillary wedge pressure $35 \mathrm{mmHg}$, transmitral gradient $10 \mathrm{mmHg}$, mean pulmonary pressure $47 \mathrm{mmHg}$, and non-significant aortic coarctation gradient $(13 \mathrm{mmHg})$.

Surgery revealed supramitral membrane, anterior commissure fusion, and posterior mitral leaflet traction to anterolateral papillary muscle due to chordae tendineae. For those reasons, mitral commissurotomy was performed, supravalvular mitral membrane resection and mitral annuloplasty. Three months after the surgery, TTE showed a mean mitral gradient of $10 \mathrm{mmHg}$, and the treadmill exercise test demonstrated an improvement in the functional class ( $>8$ metabolic equivalents [METS]).

Shone's syndrome is a rare congenital anomaly of the mitral valve, and the survival is hardly ever until adulthood. There are different treatment techniques; one of them is the mitral plasty. Echocardiography is an excellent non-invasive method to establish the correct diagnosis. ${ }^{1-4}$

\section{Conflicts of interest}

We do not have conflicts of interest.

\section{Funding}

Not financial support.

\section{Ethical disclosures}

Protection of human and animal subjects. The authors declare that no experiments were performed on humans or animals for this study.

Confidentiality of data. The authors declare that they have followed the protocols of their work center on the publication of patient data.

Right to privacy and informed consent. The authors declare that no patient data appear in this article.

\section{Supplementary data}

Supplementary data are available at Revista Archivos de Cardiología de México online (http://www.archivoscardiologia.com/frame_esp.php?id=9). These data are provided by the corresponding author and published online for the benefit of the reader. The contents of supplementary data are the sole responsibility of the authors.

\section{References}

1. Shone JD, Sellers RD, Anderson RC, Adams P Jr., Lillehei CW, Edwards JE, et al. The developmental complex of "parachute mitral valve," supravalvular ring of left atrium, subaortic stenosis, and coarctation of aorta. Am J Cardiol. 1963;11:714-25.

2. Popescu BA, Jurcut R, Serban M, Parascan L, Ginghina C. Shone's syndrome diagnosed with echocardiography and confirmed at pathology. Eur J Echocardiogr. 2008;9:865-7.

3. Díaz RO, Luna AG, Escoto MC, Partida RP, Carrillo LG, Díaz RO, et al. Complejo de Shone. Acta Méd Grupo Ángeles. 2017:15:130-4.

4. Arca ÁC, García ZS, Hernández RA, Rodríguez ML. Síndrome de Shone incompleto. A propósito de un caso diagnosticado en la adultez. Rev Cubana Med. 2012;51:267-71. 